\title{
La inútil prolongación de la agonía del artículo 294 de la Ley Orgánica del Poder Judicial (Comentario a las SSTC 8/2017, de 19 de enero, y 10/2017, de 30 de enero) ${ }^{*}$
}

\author{
Silvia del Saz
}

DOI: https://doi.org/10.47623/ivap-rvap.108.2017.08

\begin{abstract}
Sumario: I. La presentación de la cuestión. - II. Los antecedentes de los que traen causa las dos Sentencias. - III. La pequeña ceremonia de la confusión en torno a los requisitos procesales del recurso de amparo.-IV. Inadmitido el recurso de amparo por vulneración del art. $17 \mathrm{CE}$ y limitado a la vulneración del derecho a la presunción de inocencia, ¿dónde encaja el derecho a la indemnización por la prisión provisional sufrida por quien finalmente resulta absuelto?-V. La vulneración por la jurisprudencia del Tribunal Supremo del derecho a la presunción de inocencia en los términos establecidos por el Tribunal Europeo de Derechos Humanos.-VI. Los puntos de desacuerdo entre Magistrados: ¿cabe oponer resistencia a la jurisprudencia del Tribunal Europeo de Derechos Humanos?-VII. Epílogo. ¿En qué tejado está ahora la pelota?
\end{abstract}

\section{La presentación de la cuestión}

Son objeto de este trabajo dos sentencias del Tribunal Constitucional, las núm. 8 (BOE 23 febrero 2017) y 10 de 2017 (BOE 10 de marzo de 2017), dictadas en sendos recursos de amparo.

Constituyen el pistoletazo de salida de lo que, sin duda, será una larga lista de sentencias con una problemática común, la que deriva de la forma en que el art. 294 Ley Orgánica del Poder Judicial (LOPJ) regula la indemnización por la prisión provisional sufrida por quien luego no resulta condenado y de la interpretación que la Sala tercera del Tribunal Supremo ha venido realizando del mismo, antes y después del giro inaugurado por las Sentencias de la Sección Sexta de la Sala de lo Contencioso-Administrativo de 23 de noviembre de 2010 (rec. 4288/2006 y 1908/2006).

* Para un querido Maestro, Tomás de la Quadra-Salcedo. Lo prometido es deuda. 
No es del todo descartable que, cuando estas líneas vean la luz, este comentario haya quedado desfasado. El valor de las sentencias constitucionales de amparo tras la reforma en 2007 de la Ley Orgánica del Tribunal Constitucional (LOTC) reside, más allá de la reparación de la lesión sufrida (que corresponde principalmente a los órganos judiciales), en su interés para la formación de doctrina constitucional y para la corrección de sus desviaciones, así como para depurar las leyes en lo que se opongan a la Constitución [autocuestión (STC 155/2009)].

Ello requiere, sin duda, de una labor interpretativa capaz ir más allá del supuesto de hecho planteado. Esto es, de construir nuestro sistema constitucional de derechos fundamentales que no quedó congelado, como bien ha quedado demostrado en tantas y tantas ocasiones, en la realidad de 1978 y que sigue evolucionando, día a día, no sólo por el impulso de los tratados internacionales sino por la percepción misma que de ellos tenemos. Esto es, sin embargo, lo que esteTribunal no parece haber conseguido del todo en este tema, acuciado por los problemas procesales que siempre rodean el planteamiento de los recursos de amparo y demasiado empeñado, quizás, en huir de interpretaciones generales fajándose en la lucha cuerpo a cuerpo con el caso a caso.

A ello volveremos más adelante pero, entretanto, sirva como introducción al tema de estas sentencias, al margen de referencias jurisprudenciales y doctrinales que sobra ahora reiterar (1), que el art. 294 LOPJ, no modificado desde 1985, reconoce el derecho a la indemnización de quien, "después de haber sufrido prisión preventiva, sea absuelto por inexistencia del hecho imputado o por esta misma causa haya sido dictado auto de sobreseimiento libre, siempre que se le hayan irrogado perjuicios".

Como bien se puede apreciar, esta indemnización no requiere de la existencia y previa declaración del error judicial que reclama el art. 293 LOPJ: la prisión provisional, que no es al fin y al cabo sino una medida cautelar a adoptar en el procedimiento penal, bien puede haber sido legítimamente acordada conforme a las exigencias que establece la doctrina constitucional (2), y las propias de la Ley de Enjuiciamiento Criminal, aún a sabiendas de que la sentencia que se dicte no tiene que ser necesaria-

(1) Vid. DEL SAZ S. "La obligación del Estado de indemnizar los daños ocasionados por la privación de libertad de quien posteriormente no resulta condenado" RAP núm. 195/ sept.-dic. 2014, págs. 55 a 98

(2) Tal y como tiene señalado la STC $146 / 2000$ es posible imponer restricciones a un derecho fundamental aunque necesita una causa específica legalmente prevista y que la razón que lo justifique debe explicitarse para hacer cognoscibles los motivos que lo legitiman. Se trata, en definitiva, de una medida estrictamente necesaria, de aplicación subsidiaria, provisional y proporcionada a los fines que constitucionalmente la justifican que son los de asegurar el proceso lo que la distingue de otro tipo de privaciones de libertad y condiciona su régimen jurídico. 
mente condenatoria (3). Pero si el acusado resulta finalmente absuelto o es objeto de sobreseimiento libre por inexistencia del hecho, según este precepto, debe ser indemnizado. Así, el otorgamiento de la indemnización depende única y exclusivamente de la constatación de la razón que tuvo el juez penal para absolver.

La jurisprudencia contencioso-administrativa siempre ha considerado que la "inexistencia del hecho imputado" a la que se refiere el art. 294 LOPJ requiere, como condición necesaria, que haya quedado probado en el proceso penal su inexistencia. Ello es radicalmente distinto de que no haya prueba bastante de su existencia, que es lo que ocurre cuando existen indicios o sospechas pero no suficientes como para determinar una condena. $Y$ es que, si en materia penal, la prueba de la inexistencia del hecho imputado conduce al mismo resultado absolutorio que la falta de prueba de su existencia (en ello consiste el principio de presunción de inocencia o in dubio pro reo), en lo que atañe a la responsabilidad patrimonial del Estado por prisión provisional, las causas de la absolución penal son las únicas determinantes, según nuestro legislador, para diferenciar.

Si la sentencia penal tuvo dudas sobre la existencia del hecho imputado no podrá decirse, a ciencia cierta, que el hecho no haya existido y que el encausado no mereció con su comportamiento estar en prisión. En consecuencia, no debe ser indemnizado. Pero si el hecho delictivo ni siquiera ha existido para el juez penal ¿qué menos que indemnizar a quien ha sufrido prisión por ello? De ahí que se parta, para afirmar o denegar el derecho a la indemnización por la prisión preventiva sufrida, de los hechos probados de la sentencia penal y de la valoración que ésta haga de la prueba. No otra cosa permite el art. 294 LOPJ. De hecho, así está concebido.

La consideración relativa a la "inexistencia del hecho imputado" sólo prevista por el legislador para los elementos objetivos del tipo penal - el hecho-, fue tempranamente extendida por el Tribunal Supremo, con base en el derecho de igualdad, a otro supuesto no contemplado en el art. 294 LOPJ: si no existe diferencia entre quienes son absueltos por haber quedado probado que los hechos no existieron y quienes lo son por haberse probado su falta de participación -en ambos casos ha quedado despejada cualquier duda sobre su inocencia-,

(3) Que la medida cautelar se haya adoptado en el seno de un procedimiento penal, y no en otro tipo de proceso, nada añade a la necesidad de indemnizar los daños sufridos como consecuencia de la misma. Aunque se trata de un procedimiento bien diferente, donde las medidas cautelares son adoptadas siempre a instancia del demandante, la propia Ley de la jurisdicción contencioso administrativa reconoce el derecho a la indemnización por los daños sufridos por la adopción de la medida cautelar cuando la sentencia no diera la razón al demandante (art. 133.3 LJCA). 
la ley no puede darles un tratamiento diferente. Así, la indemnización contemplada en el art. 294 LOPJ debe ser reconocida a ambos bastando para ello con hacer una interpretación analógica del precepto y extender la inexistencia de los hechos a la inexistencia subjetiva o probada falta de participación.

No debe, pues, extrañar que llevada por este razonamiento, en ningún momento la jurisprudencia propusiera la idea de igualar a todos los que habían resultado absueltos. Existiendo un factor diferenciador (no es lo mismo la prueba de la inocencia que la existencia de dudas sobre ella) estaba plenamente justificado que unos fueran indemnizados y otros no. $Y$ es que, no se olvide, el derecho a la igualdad no exige otorgar un mismo tratamiento a situaciones desiguales.

Como quiera que nuestra doctrina constitucional clásica limitara los efectos del derecho a la presunción de inocencia al proceso penal y sancionador, esto es, se agotaba con la resolución administrativa sancionadora o con la judicial, ni los posteriores actos desestimatorios de la solicitud de indemnización ni las resoluciones judiciales que después las confirmaban podían vulnerarlo. Precisamente por ello, el art. 294 LOPJ, aunque obligaba a tener en cuenta, única y exclusivamente, las causas de la absolución en el proceso penal, no presentaba reparo alguno de inconstitucionalidad por vulneración de este derecho.

Pero tampoco las resoluciones administrativas y judiciales desestimatorias de la indemnización podían vulnerar otros derechos fundamentales (salvo la tutela judicial efectiva, estas últimas) anclada como estaba la reparación por la prisión provisional en el art. $121 \mathrm{CE}$, al fin y al cabo un derecho de configuración legal, y no así en el art. 17 CE.

Debe repararse sin embargo en que, con esta concepción, la libertad puede ser objeto no sólo de limitaciones generales, lo que se entiende comúnmente por delimitación del derecho, sino también de sacrificios singulares especialmente intensos y queridos por el legislador sin derecho a la indemnización. Una verdadera paradoja desde el punto de vista constitucional que, a estas alturas de la historia, ya no puede pasar desapercibida: ¿puede la Constitución exigir que sea indemnizado quien se ve despojado de su propiedad en beneficio de la colectividad, pero a la vez consentir que no lo sea quien se ve privado de los derechos inherentes a su personalidad, cuando luego no resulta condenado, y no, precisamente, en su propio beneficio sino en aras del interés común?

Pues bien, estas eran las aparentemente tranquilas aguas por las que navegaba la cuestión hasta que se desató la tormenta de la mano de la jurisprudencia del Tribunal Europeo de Derechos Humanos, que extendió el derecho a la presunción de inocencia, más allá de la sentencia penal, a todo lo relacionado con ella. Esto es, tanto a las cuestiones no pe- 
nales planteadas en el proceso (las costas procesales) como a las surgidas en procesos posteriores que traían causa de la sentencia penal (4).

De esta forma, el citado derecho impide, de acuerdo con el Tribunal de Estrasburgo, que la causa de la absolución por la sentencia penal y, en especial, la existencia de indicios de culpabilidad sea la única razón que sustente la denegación de la indemnización por la prisión provisional, pues ello, se diga cómo se diga y sean cuales sean las expresiones utilizadas, mantiene vivas, aún después de la sentencia, las sospechas de la falta de inocencia que deberían haber sido borradas definitivamente por la sentencia absolutoria.

Cierto es, dice el Tribunal de Estrasburgo, que el Convenio europeo no exige que se indemnice por error judicial salvo cuando se revisan las sentencias condenatorias por un hecho nuevo o nuevas revelaciones (art. 3 del Protocolo $7 \mathrm{CEDH}$ ), y menos aún como consecuencia de la privación de libertad cuando es legítimamente acordada (art.5 CEDH). Pero si los Estados miembros deciden indemnizar a quien luego no resulta condenado por la prisión provisional legítimamente ordenada, que no sea por el sólo hecho de que la sentencia penal tuvo en cuenta la existencia o no de indicios de la falta de inocencia, pues eso es tanto como impedir que el derecho a la presunción de inocencia produzca todos sus efectos que, como se viene de exponer, no se agotan en la sentencia absolutoria.

De forma absolutamente nítida lo viene a señalar, de nuevo, la STEDH de 16 de febrero de 2016 (Vlieeland Boddy Marcelo Lanni c. España) que constituye ya la tercera sentencia contra España por la aplicación del art. 294 LOPJ: "EITEDH apunta que, en aplicación del principio in dubio pro reo, ninguna diferencia cualitativa debe existir entre una absolución fundada en la inexistencia de pruebas y una absolución resultante de una constatación de la inocencia de manera incontestable. En efecto, las sentencias absolutorias no se diferencian en función de los motivos aducidos por el juez de lo penal. Muy al contrario, en el ámbito del art. 6.2 del Convenio la parte resolutiva de la sentencia absolutoria debe ser respetada por cualquier autoridad que se pronuncie de manera directa o incidental sobre la responsabilidad penal del interesado" (5).

En este contexto, el Tribunal Supremo no tenía por menos que reaccionar y lo hizo por el camino más sencillo, esto es, el que aparente-

(4) SSTEDH de 25 de abril de 2006, as. Puig Panella contra España, de 13 de julio de 2010 as. Tendam c. España, y 16 de febrero de 2016 as. Vlieeland Boddy y Marcelo Lanni c. España.

(5) La cursiva es mía. 
mente menos problemas prácticos y teóricos podía ocasionar (6). Aprovechando que las sentencias condenatorias a España se habían dictado en supuestos en que la indemnización se había rechazado porque no había quedado probada la falta de participación en el hecho delictivo aun cuando los indicios no habían llevado a la convicción del juzgador sobre su culpabilidad, lo hizo suprimiendo la interpretación analógica entre la inexistencia objetiva y subjetiva de los hechos que venía realizando desde hacía veinticinco años por aplicación del art. 14 CE: si el problema era, según elTribunal Europeo de Derechos Humanos, que no se podía tener en cuenta la existencia o no de indicios sobre la participación, había que excluir del derecho a la indemnización que reconoce el art. 294 LOPJ a todas las sentencias absolutorias que versaran sobre la falta de participación en el hecho delictivo para no tener que distinguir en función de la prueba de la no participación o de la no existencia de prueba de cargo suficiente. Al fin y al cabo, siempre podrían reclamar los instantes de la indemnización por un error judicial que no se había producido cuando la prisión provisional ha sido legítimamente acordada. Y aún así se dolía la sección sexta del Tribunal Supremo en aquellas dos primeras sentencias de 23 de noviembre de 2010, de que no otra cosa podía hacer dado el tenor literal del precepto. No se atrevió entonces a plantear cuestión de inconstitucionalidad del art. 294 LOPJ por vulnerar el citado derecho, como, sin embargo, lo había hecho en anteriores ocasiones.

Como era del todo previsible, muerto el perro no se acabó la rabia, aunque la tregua ha durado nada menos que siete años.

La solución de compromiso, ya insuficiente desde su nacimiento, ha demostrado serlo por cuanto el art. 294 LOPJ sigue estando vigente en los mismos términos: aún excluida la inexistencia subjetiva de los hechos, el art. 294 LOPJ sigue obligando a tener en cuenta la prueba de la falta de existencia objetiva de los hechos y, por tanto, si la absolución lo ha sido por aplicación del derecho a la presunción de inocencia. Tanto es así que las dos sentencias que son objeto de este comentario versan no ya sobre la participación, sino sobre el supuesto de hecho considerado, más allá de interpretaciones extensivas, por el art. 294 LOPJ. Esto es, sobre la inexistencia del hecho imputado.

(6) El planteamiento de una cuestión de inconstitucionalidad conlleva la paralización de la tramitación de todos los recursos judiciales en tanto en cuanto no se resuelva, y en el año 2010 el tremendo retraso del Tribunal Constitucional en la resolución de recursos y cuestiones de inconstitucionalidad era una realidad. Por otra parte, creo que formaba parte de la convicción general de entonces, quizás de la todavía hoy imperante, que otra forma de reconocimiento de indemnización por prisión provisional distinta de la contemplada en el art. 294 LOPJ podía poner en jaque la eficacia del sistema penal. 


\section{Los antecedentes de los que traen causa las dos Sentencias}

La STC 8/2017 se dicta en un supuesto en que el demandante de amparo había sufrido prisión provisional durante casi catorce meses por un delito contra la salud pública, siendo así que se le había detenido transportando dos sacos, una bolsa y un envoltorio que contenía 30.011.87 gramos en forma de cápsulas de una sustancia que, tras ser analizada en numerosas ocasiones, había dado resultados varios cuya naturaleza, tipo, características y peso no resultaron acreditadas, desconociéndose de qué sustancia se trataba en realidad, y por ende si dicho producto causaba grave daño a la salud. El demandante resultó absuelto en primera instancia.

No hay constancia en los antecedentes de la sentencia de amparo de la motivación de la resolución administrativa que desestimó la solicitud de indemnización al amparo del art. 294 LOPJ, pero sí de la motivación de la Sentencia de la Audiencia Nacional que confirmó la resolución desestimatoria, cuyos fundamentos jurídicos segundo y tercero reproduce literalmente.

En el fundamento segundo, la Audiencia Nacional da cuenta con carácter general de la evolución experimentada en la interpretación del art. 294 LOPJ - es un fundamento tipo común a la mayoría de las sentencias de este órgano judicial-. En el tercero, que lo es ya de aplicación de la jurisprudencia al caso concreto, tras recordar la sentencia de la Audiencia Nacional que el demandante basa su pretensión en la inexistencia del hecho imputado, revisa la motivación de la sentencia penal para afirmar que «De la lectura de la reseñada Sentencia y del procedimiento penal, se desprende que el Tribunal penal tras analizar las pruebas existentes en relación con los varios análisis contradictorios realizados a la sustancia que transportaba el aquí actor, no llegó a la convicción de que estuviese probada la concurrencia de uno de los elementos que integraban el tipo del delito, en concreto, la existencia de una sustancia tóxica, pero tampoco se desprende de la misma que hubiese quedado demostrado que no fuese dicha sustancia que causa grave daño a la salud pública, y, por lo tanto, la inexistencia objetiva del delito. El Tribunal alberga dudas razonables sobre este elemento del tipo penal y, por lo tanto, en aplicación del principio in dubio pro reo, absuelve al acusado".

Por lo que concluye "No se puede confundir el defecto o insuficiencia en la prueba acerca de lo que es la acción delictiva, que es lo que ocurrió en el caso de autos, ya que se parte de la existencia de la prueba aunque el Tribunal penal entienda al valorarla, que no es apta para fundamentar una sentencia condenatoria, con la prueba de la inexistencia del hecho imputado. En consecuencia, procede desestimar el recurso contenciosoadministrativo». 
Exactamente lo mismo hizo la sentencia del Tribunal Supremo al resolver el recurso de casación contra la sentencia dictada en única instancia por la Audiencia Nacional. Recuerda el Tribunal Supremo que el derecho a la presunción de inocencia que consagra el Convenio Europeo de derechos humanos no exige en todo caso indemnización y que la interpretación del art. 294 LOPJ debe seguir realizándose como antaño(7).Y esto es lo que hace, ni más ni menos, al revisar la aplicación al caso concreto realizada por la sentencia recurrida en casación: «la sentencia de instancia analiza las conclusiones de la sentencia penal para observar que la absolución del hoy recurrente se produjo no por inexistencia del hecho imputado sino por falta de prueba respecto a la concurrencia de todos los requisitos del tipo penal tal y como resulta el mismo tipificado en el Código Penal y ello no significa que el hecho no existió, sino que el Tribunal tuvo dudas razonables y procedió a absolver al recurrente. Por ello, no nos encontramos ante un supuesto indemnizable por ser la prisión provisional seguida de una sentencia absolutoria que declare la inexistencia objetiva del hecho, sino que es una absolución sustentada en la aplicación de los principios rectores del proceso penal (presunción de inocencia)». Para terminar recordando que el art. 294 LOPJ es un supuesto específico de error judicial del art. $121 \mathrm{CE}$, de manera que no dándose los requisitos que exige este precepto, siempre podrá el demandante acogerse a la vía establecida en el art. 293 LOPJ que requiere la previa declaración del error judicial (8) .

(7) «La interpretación y aplicación del artículo 294.1 LOPJ ha de mantenerse, en todo caso, dentro de los límites y con el alcance previstos por el legislador, que en modo alguno contempla la indemnización de todos los casos de prisión preventiva que no vaya seguida de sentencia condenatoria, ni siquiera de todos los casos en los que el proceso termina por sentencia absolutoria o auto de sobreseimiento libre, planteamiento que, por lo demás y según se desprende de las referidas antes sentencias delTEDH, no supone infracción del art. 6.2 del Convenio, pues, como se indica en las mismas, ni el art. 6.2 ni ninguna otra cláusula del Convenio dan lugar a reparación por una detención provisional en caso de absolución y no exigen a los Estados signatarios contemplar en sus legislaciones el derecho a indemnización por prisión preventiva no seguida de condena".

(8) «No ha de perderse de vista que, como ya hemos indicado al principio, el art. 294 de la LOPJ contempla un supuesto especifico de error judicial, que no está sujeto a la previa declaración judicial del mismo exigida con carácter general en el art. 293 de la LOPJ, configurando un título de imputación de responsabilidad por el funcionamiento de la Administración de Justicia, consistente en la apreciación de error judicial en la adopción de la medida cautelar de prisión provisional, que el legislador entiende que se revela cuando la resolución penal de absolución o sobreseimiento libre se produce "por inexistencia del hecho imputado" y no de manera genérica o en todo caso de absolución o sobreseimiento libre. Como ya hemos dicho reiteradamente queda abierta al actor la vía del artículo 293.2 de la Ley Orgánica del Poder Judicial, ya que esta nueva y ya consolidada interpretación no supone dejar desprotegidas las situaciones de prisión preventiva seguida de sentencia absolutoria o sobreseimiento libre, que venían siendo indemnizadas como inexistencia subjetiva al amparo de dicho precepto, sino que con la modificación del criterio jurisprudencial tales reclamaciones han de remitirse a la vía general prevista en el art. 293 de la LOPJ". 
En el caso que da lugar a la STC 10/2017, el recurrente había sufrido prisión provisional durante casi cuatro años por un delito de integración en banda armada por el que fue condenado en primera instancia pero absuelto en casación, porque no había quedado probado, más allá de que estaba inmerso fanáticamente en teorías fundamentalistas, que hubiera aceptado participar de alguna forma en la imposición de estas ideas mediante la violencia terrorista.

Instada la indemnización por la vía del art. 294 LPOJ, la resolución administrativa la deniega haciendo suyo el razonamiento del informe del Consejo de Estado: "[d]e forma muy escueta, la sentencia [de casación] reconoce la admiración y sujeción a las predicaciones de otro coencausado y condenado y destaca, incluso, la comunión o aceptación de sus ideas fundamentalistas... Por lo tanto, el Alto Tribunal constata unas determinadas relaciones entre los acusados aunque valora las declaraciones y confesiones de creencias en el sentido de que no acreditan la existencia de una integración en banda armada. Dicho en otros términos, la absolución se basa en que la prueba que obra en autos es insuficiente para apreciar la existencia del delito imputado y no, por el contrario, en que los acusados estuviesen nítidamente desvinculados de los hechos que se les imputaron», por lo que llega a la conclusión de que «no se dan los requisitos exigidos" en el art. 294 LOPJ».

La sentencia de la Audiencia Nacional confirma la resolución administrativa ya que por aplicación de la jurisprudencia del Tribunal Supremo "la Sala considera que el art. 294 LOPJ no resulta aplicable al caso, pues, según se razona, "el actor fue absuelto del delito de integración en organización terrorista porque la prueba que constaba en los autos era insuficiente para apreciar el citado delito, no por la inexistencia objetiva del hecho, siendo otros imputados condenados en la misma causa por el delito de integración en banda terrorista" ".

Como se puede apreciar, la desestimación de la reparación solicitada en ambos casos ex art. 294 LOPJ se ciñe a la interpretación que la jurisprudencia venía haciendo de la inexistencia del hecho imputado que exige que la sentencia penal haya llegado a la absolución por la prueba de la falta de existencia que no se da, sin embargo, cuando el tribunal penal alberga dudas razonables sobre la existencia de elementos del tipo delictivo. En ambos casos, la desestimación se basa en la causa que la sentencia penal ha tenido en cuenta para llegar a la absolución, denegándose automáticamente porque lo ha sido por aplicación del derecho a la presunción de inocencia. Precisamente lo que exige el art. 294 LOPJ. 


\section{La pequeña ceremonia de la confusión en torno a los requisitos procesales del recurso de amparo}

Podría decirse que la defensa de los derechos fundamentales se ha convertido en una disciplina con entidad propia, una suerte de derecho procesal específico dado que los requisitos formales para su denuncia han devenido en el mayor obstáculo para el reconocimiento de su lesión y su correspondiente reparación. De ello constituyen un inmejorable ejemplo las sentencias que son objeto de este comentario.

Como es sabido, las lesiones de derechos fundamentales objeto de recurso de amparo constitucional pueden proceder de la resolución administrativa (art. 43 LOTC) o de la resolución judicial en cualquiera de las instancias (art. 44 LOTC) o de los dos de forma combinada cuando a la lesión por la resolución administrativa de un derecho fundamental se añade una lesión ex novo de otros derechos fundamentales por las resoluciones judiciales, dándose así el supuesto de un recurso de amparo mixto. Lo importante, sea cual sea el caso, es que la denuncia de la lesión producida (así lo exige el art. 44 LOTC y la doctrina constitucional lo ha extendido también al art. 43 LOTC) se realice en el primer momento en que se tenga ocasión y que se dé al órgano judicial la oportunidad de corregirla pues, en otro caso, dada la naturaleza objetiva del recurso de amparo constitucional, podría haber lesiones que quedaran sin reparación.

Así, tratándose de la lesión de un derecho fundamental ocasionado por la resolución administrativa (art. 43 LOTC) deberá denunciarse en el recurso contencioso-administrativo interpuesto contra la misma, de manera que la confirmación del acto por la sentencia de primera instancia, y en su caso, por la dictada en la instancia siguiente, no convierte el recurso en un recurso de amparo del art. 44 LOTC, ni tampoco en un recurso mixto salvo que la sentencia añada a la anterior una nueva lesión (normalmente del art. $24 \mathrm{CE}$ ) que deberá denunciarse mediante el recurso procesal que corresponda o, en caso de no existir, mediante el incidente de nulidad de actuaciones. Esto es, el incidente de nulidad de actuaciones solo tiene sentido para reparar aquellas nuevas lesiones de derechos fundamentales ocasionadas por las resoluciones judiciales contra las que no cabe recurso procesal alguno pero no es procedente cuando la lesión se ha producido antes y pudieron ser corregidas. Finalmente, no está de más señalar que en el recurso de amparo del art. 43 LOTC el derecho fundamental cuya lesión se invoque debe ser susceptible de vulneración por la resolución administrativa y, esto era lo novedoso del tema por cuanto, como anticipamos, hasta el momento de dictarse estas sentencias, una resolución administrativa no sancionadora, no podía vulnerar el derecho a la presunción de inocencia. 
Pues bien, en el recurso de amparo del que trae causa la STC 10/2017, la única lesión invocada lo fue del derecho de presunción de inocencia, tanto en el recurso contencioso administrativo que se ventiló en una sola instancia como, después ya, en el recurso de amparo. Es por ello que, frente a la alegación del Abogado del Estado de que el recurso debía ser inadmitido por no haberse planteado nulidad de actuaciones, la sentencia realiza el razonamiento correcto: si de lo que se trata es de extender o no el efecto del derecho a la presunción de inocencia más allá del dictado de la sentencia penal, a todo lo con ella relacionado, la resolución administrativa que desestima la indemnización también podrá vulnerar este derecho. De ahí que como quiera que la sentencia se limita a no reparar la vulneración ya cometida por la resolución administrativa, no sea necesario plantear nulidad de actuaciones que sólo habría sido procedente si la lesión del derecho se hubiera producido ex novo por la sentencia dictada en única instancia, pues solo en este caso el Juez no habría tenido ocasión de pronunciarse sobre ello. Y en atención a que se trata de un recurso de amparo ex art. 43 LOTC, el Fallo de la sentencia constitucional, al estimar la vulneración alegada, anula tanto la sentencia como la resolución administrativa impugnada para que se dicte por la administración una nueva resolución sin incurrir en la lesión apreciada. En definitiva, una resolución administrativa no sancionadora puede vulnerar, también, el derecho a la presunción de inocencia lo que implica una modificación esencial de nuestra doctrina constitucional clásica.

Este razonamiento que la STC 10/2017 expone de forma tan clara, briIla por su ausencia en la sentencia que la precede. Entiende aquella, pegada a la literalidad del recurso de amparo, que como sólo se interpone contra la sentencia del Tribunal Supremo, sólo pueden analizarse las lesiones de derechos fundamentales con origen inmediato y directo en ésta sentencia sin que «pueda extenderse a la resolución administrativa ni consiguientemente a la reparación pretendida que aquella niega». Pero si esto fuera realmente así, resulta que no habría sido posible interponer el recurso de amparo sin previamente acudir a la nulidad de actuaciones, incidente que el Tribunal Constitucional no exige en este caso.

Después, a pesar de lo que afirma inicialmente, imputa las lesiones, no ya a la sentencia del Tribunal Supremo, sino a la sentencia de la Audiencia Nacional a los efectos de comprobar si la pretendida lesión se denunció en el primer momento en que se tuvo ocasión pues sólo admite las lesiones que fueron invocadas en casación, pero no así la lesión del art. 17 CE que dice haberse introducido ex novo en el recurso de amparo. Pero ignora a la vez que si la resolución administrativa se basó, como todo parece indicar - los antecedentes de la sentencia no recogen su motivación-, en la aplicación de esta jurisprudencia, es ésta la que podría haber vulnerado los derechos fundamentales y por tanto la denuncia de 
la lesión debía haberse realizado en todo caso en el recurso contencioso administrativo, y, si no, no podría haberse admitido el amparo.

Para finalmente volver al discurso inicial: la lesión se habría producido por la sentencia del Tribunal Supremo pues es ésta la única la que anula dejando vivas y coleando tanto la resolución administrativa como la sentencia de la Audiencia Nacional con motivaciones idénticas a la que finalmente lleva a la sentencia a declarar que ha vulnerado el derecho fundamental y anula.

No sólo por ser posterior la STC 10/2017, sino también por su coherencia con los requisitos procesales exigidos para los amparos constitucionales, debemos quedarnos con lo que de ella se deduce: la vulneración de derechos fundamentales cuando se desestima la indemnización por las causas contempladas en el art. 294 LOPJ se produciría, en su caso, por la resolución administrativa y, por tanto, el recurso de amparo deberá prepararse como recurso del art. 43 LOTC, denunciando la lesión en vía contencioso administrativa, agotando todos los recursos judiciales y sin tener que interponer nulidad de actuaciones, salvo que la sentencia contra la que no cabe recurso procesal añada alguna otra lesión nueva de otro derecho fundamental (incongruencia, falta de motivación, etc.).

\section{Inadmitido el recurso de amparo por vulneración del art. 17 CE y limitado a la vulneración del derecho a la presunción de inocencia, ¿dónde encaja el derecho a la indemnización por la prisión provisional sufrida por quien finalmente resulta absuelto?}

Una vez inadmitida por la STC 8/2017 la causa consistente en la vulneración del art. $17 \mathrm{CE}$ - su invocación, ya en el recurso de amparo, fue extemporánea- y centrado éste en el art. 24.2 CE, el Tribunal podía haber entrado sin mayores preámbulos a analizar la lesión pretendida del derecho a la presunción de inocencia. No lo hace así, sin embargo, pues recuerda para suscribirla, a modo de fundamento previo, la doctrina que hace derivar del art. $121 \mathrm{CE}$ la indemnización contemplada por el art. 294 LOPJ, lo que implícitamente le lleva a descartar la lesión del art. $17 \mathrm{CE}$.

Por todo razonamiento, la sentencia afirma que la Ley Orgánica del Poder Judicial desarrolla el art. 121 CE distinguiendo el error judicial (293 LOPJ) de la prisión preventiva (art. 294 LOPJ) siendo el error judicial en la mencionada ley un concepto jurídico indeterminado requerido de ser precisado casuísticamente desde el plano de la legalidad por los jueces y tribunales, doctrina que así mismo resulta aplicable a las reclamaciones de responsabilidad que se basan en haber sufrido prisión provisional por unos hechos de los que luego resulta absuelto y encuentran su especial 
regulación en el art. 294 LOPJ, omitiendo que este último precepto, a diferencia de lo que ocurre con el error judicial, precisa con claridad cuándo se produce este supuesto error: cuando el hecho imputado no ha existido de acuerdo con la valoración de los hechos realizados por la sentencia penal. Realmente, el art. 294 LOPJ permite un escaso margen de apreciación en cuanto a su interpretación.

Señala a continuación que en otras legislaciones de derecho comparado se contienen preceptos similares y que el Convenio Europeo no exige la indemnización de quien es objeto de prisión provisional adoptada legalmente de quien luego es absuelto, por lo que no resulta incompatible con ninguna cláusula del convenio un régimen jurídico que la limita o excluya en determinados supuestos, y concluye con la idea de que el Tribunal Supremo ha declarado, en la interpretación del art. 294 LOPJ que nuestro sistema normativo no avala la conclusión de una responsabilidad patrimonial y automática y objetiva de tal manera que, una vez producida la absolución o el sobreseimiento libre se generara en quien hubiera sufrido un derecho indemnizatorio.

Pero, ¿qué es lo que manda la Constitución? ¿Es realmente la prisión preventiva legítimamente acordada un error judicial cuando se adopta sobre la base y a sabiendas de que la sentencia no necesariamente habrá de ser condenatoria? Y si esto es así, si no existiera error, ¿la reparación contemplada en el art. 294 LOPJ, es un derecho de creación legal sin anclaje constitucional alguno, que puede libre y discrecionalmente suprimirse por el legislador (9) para todos los casos sea cuál sea la duración de la prisión, el comportamiento del encausado y los daños ocasionados? ¿Consiente la Constitución, consiente el art. $17 \mathrm{CE}$, que se pueda excluir en todo caso la indemnización de quienes resultan absueltos?

Aunque la respuesta afirmativa a la última de las preguntas es la que parece deducirse de la sentencia constitucional, tampoco lo afirma expresamente con soporte en razones que trasciendan la legalidad ordinaria, el derecho comparado o las exigencias de obligado cumplimiento del Convenio Europeo de Derechos Humanos, de manera que no puede darse este problema por definitivamente zanjado, aunque sí en el caso concreto, por haber quedado excluido de este amparo la lesión del art. $17 \mathrm{CE}$.

(9) Véase DOMENECH PASCUAL, G., «El error de la responsabilidad patrimonial del Estado por error judicial", en RAP núm. 199, enero-abril 2016, pág. 196 cuando alega razones que desde el punto de vista de la eficiencia hacen que sea mejor resarcir los daños ocasionados a los acusados como consecuencia de su prisión provisional seguida de absolución, ya que se mejora la eficacia preventiva del derecho penal al aumentar el atractivo de ser inocente, debiéndose valorar si se hace con el estándar "cuando la inocencia queda suficientemente acreditada mas allá de toda duda razonable" o se opera con el criterio menos estricto de la probabilidad preponderante «quienes hayan acreditado suficientemente su inocencia» 


\section{La vulneración por la jurisprudencia del Tribunal Supremo del derecho a la presunción de inocencia en los términos establecidos por el Tribunal Europeo de Derechos Humanos}

Centrada la cuestión en la vulneración del derecho a la presunción de inocencia, la STC 8/2017 (FJ 6), tras exponer cuál había sido la doctrina clásica delTribunal sobre este derecho, viene a señalar que la jurisprudencia del Tribunal Europeo de Derechos Humanos ha ampliado su alcance ya que no limita sus efectos al dictado de la sentencia penal, extendiéndolo a los procesos judiciales consecutivos a la absolución definitiva del acusado en la medida en que las cuestiones planteadas en dichos procesos constituyan un corolario o complemento de la sentencia penal, lo que ocurre cuando se tiene en cuenta, entre otros, el motivo por el que la sentencia absolvió al solicitante de la indemnización.

Es, por tanto, la interpretación extensiva del derecho a la presunción de inocencia conforme al Convenio Europeo de Derechos Humanos, más allá de la sentencia penal, la que hace al Tribunal Constitucional modificar su anterior doctrina, pues analiza desde este nuevo prisma la motivación de la sentencia del Tribunal Supremo, que confirma la desestimación de la indemnización solicitada (FJ 7).

Una vez aceptada la extensión al procedimiento indemnizatorio del derecho de presunción de inocencia, tras avisar que esta sentencia no aborda la probada falta de participación por no afectar al supuesto en cuestión, la sentencia de la mayoría pasa a analizar si se ha vulnerado o no, para lo que prosigue diciendo que el Tribunal Europeo ha considerado lesivas de este derecho resoluciones administrativas y judiciales en materia de responsabilidad y, léase bien, administrativas y judiciales, "que expresaron la distinción entre la absolución por haber quedado probada la no participación en los hechos y la absolución por falta de prueba de tal participación, argumentando que tal motivación sin matices ni reservas deja latente una duda sobre la inocencia del demandante", citando a continuación las tres sentencias condenatorias a España a las que ya se ha hecho referencia.

Y como quiera que la sentencia del Tribunal Supremo razona que «la absolución está sustentada en la aplicación de los principios rectores del proceso penal (presunción de inocencia) derivando de ahí que no concurre el presupuesto de hecho de la inexistencia del hecho delictivo" hay que estimar que dicha resolución vulnera el derecho a la presunción de inocencia, pues emite sospechas sobre la culpabilidad del recurrente $y$ "utiliza la referencia a dicho derecho como elemento integrador de la relación de causalidad del daño producido en el ámbito de la responsabilidad patrimonial, lo que se estima inadecuado, pues para determinar si concurre o no la responsabilidad de la administración de justicia por pri- 
sión provisional no podrán utilizarse argumentos que ni directa ni indirectamente afecten a la presunción de inocencia».

Concluye, así, este fundamento, en que se aprecia a vulneración del derecho porque el razonamiento de la sentencia del Tribunal Supremo que es objeto del recurso de amparo pone en duda la inocencia del demandante, ya que utiliza las mismas expresiones contenidas en la STEDH de 13 de julio de 2010 en el as. Tendam c. España, por la motivación empleada o el lenguaje utilizado en su razonamiento, que le llevaron a declarar que cuestionaban la inocencia del demandante, para reproducir a continuación la más reciente STEDH de 16 de febrero de 2016, la última condenatoria a España, en el que se había desestimado la indemnización reclamada, una vez más, por aplicación del art. 294 LOPJ y teniendo exclusivamente en cuenta los motivos de la absolución penal.

\section{Los puntos de desacuerdo entre Magistrados: ¿cabe oponer resistencia a la jurisprudencia del Tribunal Europeo de Derechos Humanos?}

El primer punto de desacuerdo entre Magistrados, tal y como se pone de manifiesto en el voto particular suscrito por dos de los nueve que estaban presentes en el Pleno en que se aprobó la sentencia(10), consiste en la extensión que debe darse al derecho a la presunción de inocencia. Así, el voto particular llega a afirmar que el proceso contencioso-administrativo en el que se dirime si el recurrente tiene derecho a indemnización «no es un ámbito sobre el que se proyecte el derecho a la presunción de inocencia ex art. 24.2 CE pues en él no se hace ninguna valoración de culpabilidad de quien reclama ser indemnizado que pueda conducir a un reproche sancionador. En dicho proceso solo se analizó si concurrieron los presupuestos legales para que surja el derecho a ser indemnizado, aspecto típico de la legalidad ordinaria y ajeno al ámbito constitucional, máxime cuando la jurisdicción contencioso administrativa respetó, escrupulosamente, el previo pronunciamiento penal» (FJ 7 del voto particular).

Un rechazo, sin duda motivado, que no hace sino reiterar nuestra doctrina constitucional clásica sobre la limitación del principio de presunción de inocencia al procedimiento sancionador o penal, doctrina que ha sido desautorizada por una ya larga serie de sentencias del Tribunal Europeo

(10) Los dos magistrados del Tribunal Constitucional ausentes habían intervenido, como Magistrados del Tribunal Supremo, en la aprobación de la sentencia de la que trae causa el recurso de amparo. No debe pasar desapercibido, sin embargo, que otros magistrados que componen el Pleno del Tribunal Constitucional participaron en otras sentencias que aplican la misma doctrina aunque no se hayan abstenido en este caso por no estar directamente afectados por el asunto. 
con base en los argumentos que bien resume la STEDH de 12 de junio de 2013 as. Allen c. Reino Unido cuya doctrina el propio voto particular invoca: "Cada vez que la aplicabilidad de este precepto (art. 6.2 CEDH)se plantea en un procedimiento posterior, el demandante deberá demostrar que existe un vínculo entre el procedimiento penal finalizado y la acción subsiguiente, vínculo que puede estar presente, por ejemplo, cuando en el proceso posterior hace falta examinar el curso del procedimiento penal y particularmente cuando se obliga a la jurisdicción competente a analizar el juicio penal, a realizar un estudio o una evaluación de los elementos de prueba en el proceso penal, a realizar una apreciación sobre la participación del reclamante en uno o el conjunto de acontecimientos de los que se haya concluido su condena, o a formular comentarios sobre las indicaciones que continúen sugiriendo una eventual culpabilidad" (aptdo. 104).

¿Cabe acaso alguna duda de que el art. 294 LOPJ remite al procedimiento judicial penal previo y obliga a tener en cuenta los hechos del proceso penal y la valoración que de los mismos ha realizado el juez penal cuando establece como única causa de indemnización que el sometido a prisión haya sido absuelto por la sentencia penal por inexistencia del hecho imputado? En términos de la jurisprudencia europea es seguro que el pronunciamiento basado en estas razones - la que tuvo en cuenta el órgano judicial penal para absolver - está vinculado por el contenido esencial del derecho a la presunción de inocencia. Así lo ha afirmado el Tribunal Europeo, nada más ni nada menos que en tres ocasiones, a la vista del art. 294 LOPJ, considerando la única causa que debe tenerse en cuenta, conforme a este precepto, para reconocer o desestimar la indemnización. No queda, en consecuencia, margen alguno para la interpretación del alcance de este derecho en otro sentido, por muy sutil y matizada que ésta sea.

El segundo punto de desencuentro entre magistrados es el relativo a la forma en que ha de interpretarse la jurisprudencia europea. Los autores del voto particular no están de acuerdo con la interpretación de la jurisprudencia del Tribunal Europeo que luce en la sentencia de la mayoría. O, mejor dicho, entienden que las sentencias de condena a España por aplicación del art. 294 LOPJ, aún siendo sentencias de este mismo Tribunal, no siguen su jurisprudencia.

Así, consideran que existen otras sentencias de este mismoTribunal que permiten alcanzar en los procesos de indemnización conclusiones distintas respecto de las pronunciadas en el proceso penal sin que ello suponga la violación de la presunción de inocencia, esto es, permite que se realice en el procedimiento indemnizatorio una valoración legal separada basada en estándares de prueba distintos en algunos aspectos de otros aplicables en el proceso penal, como en el caso de la STEDH de 13 de noviembre de 2013, as. Lundkvist c. Suecia, donde se razonó para denegar la indemniza- 
ción solicitada por quien había sido absuelto del delito de incendio que «no ha aportado ninguna explicación del origen del fuego. Ha tenido buenas oportunidades para prender fuego. De acuerdo con la investigación, justo antes del fuego entró y salió de la casa varias veces»(11), siendo así que esta jurisprudencia se resume, en su opinión en la STEDH de 12 de junio de 2013, as. Allen c. Reino Unido, a partir de la concurrencia de dos elementos: a) el lenguaje utilizado por el órgano decisor es de vital importancia para valorar la compatibilidad del razonamiento de una decisión con el derecho a la presunción de inocencia, y b) sin embargo, cuando se centra la atención en la naturaleza y el contexto concreto de un proceso, incluso el uso desafortunado del lenguaje puede no ser determinante(12).

(11) Se omite señalar el contexto en que tuvo lugar la sentencia que se somete a la consideración del Tribunal Europeo. Se trataba en este caso un procedimiento de indemnización por los daños ocasionados en su domicilio por el incendio de su casa, del que había sido absuelto quien ahora reclama indemnización. En este caso, órgano judicial civil tomó algunos hechos de los que se habían considerado probados en el proceso penal, de las nuevas pruebas que se practicaron en proceso civil, así como tuvo en cuenta que en el procedimiento de indemnización el reclamante no había sido capaz de dar una explicación sobre el origen del fuego mientras que sin embargo había salido varias veces de la casa, y tenía motivos para prenderle fuego. Como se puede comprobar, un estándar de prueba alejado por completo de la mera constatación de los motivos que han llevado al juez a su absolución, como ocurre en nuestro caso.

(12) La sentencia as. Allen c. Reino Unido que se invoca en el voto particular versa sobre la denegación de la indemnización contemplada por la ley inglesa de 1988 por la revisión de sentencias penales firmes (art. 3 Protocolo 7 TEDH) que, como se dijo, es el único supuesto en que el Convenio exige indemnización por error judicial. Este precepto exige se acredite que fue condenado, y que posteriormente se anule la condena porque un hecho nuevo demuestre más allá de toda duda razonable que se ha producido un error. Habiendo sido condenada la Sra. Allen por asesinato -el jurado entendió que las lesiones de su hijo habían sido causadas por una actuación violenta - y cuando ya había cumplido una parte de la pena, solicitó la revisión de la sentencia aportando nuevos testimonios médicos que partían de la base de que no podía demostrarse que las lesiones constatadas fueran derivadas de la violencia (nuevos elementos). El tribunal de revisión entiende que no le corresponde realizar la valoración de la prueba pero si determinar si la condena tiene una base sólida concluyendo que no la tiene porque de haberse conocido estos documentos médicos por el Jurado podrían haber influido en el resultado de la sentencia. Así pues, la anula aunque no ordena dictar una nueva sentencia por cuanto ya estaba ejecutada y de nada habría servido.

Anulada la sentencia, la demandante reclama indemnización por la prisión sufrida al amparo del art.133 de la Ley inglesa que exige se acredite que fue condenado, y que posteriormente se anule la condena porque un hecho nuevo demuestre más allá de toda duda razonable que se ha producido un error. El ministerio la rechaza por entender que los elementos médicos examinados por el tribunal de revisión no revelan un hecho nuevo o de nueva revelación, se trata más bien de elementos que demuestran la evolución de la ciencia en cuanto a la intensidad de la fuerza necesaria para causar las lesiones lo que no son hechos nuevos sino de elementos nuevos que conciernen a los mismos hechos que se tuvieron en cuenta desde el principio.

Recurrida esta resolución ante los tribunales, la sentencia para analizar si existió un error en la condena, más allá de toda duda que se hubiera puesto de manifiesto por los documentos aportado, parte del razonamiento de la sentencia de instancia para concluir que habida cuenta de que no había realizado una valoración de la prueba no era posible afirmar que el jurado habría adoptado otra decisión, por lo que entiende que el error más allá de toda duda no se había producido, por lo que concluye que la sentencia que desestima la indemnización tiene en cuenta que la sentencia de revisión se limita a decir que los elementos nuevos hace surgir la posibilidad de que combinados con los ya conocidos el jurado podría quizás haber emitido un diferente veredicto, lo que demuestra que se está muy lejos de la duda razonable de que haya existido un error. 
Así pues, concluye el voto particular que en aplicación de esta doctrina, la motivación y el lenguaje empleado por la Sentencia del Tribunal Supremo argumentando en relación a la responsabilidad patrimonial, no habría lesionado la presunción de inocencia pues (i) no ha puesto en duda la inocencia del demandante, ya que tanto la sentencia penal como la contencioso administrativa se limitaron al estadio previo al del análisis de la culpabilidad y sólo valoraron las dudas existentes a los efectos de quedar encuadradas en el art. 294, llegando al convencimiento de que no se había cumplido con el presupuesto de este precepto, e incluso (ii) en el caso del uso desafortunado del lenguaje, que no se ha producido en este caso, las manifestaciones que se hacen en relación a si el interesado tiene derecho a la indemnización ex art. 294 LOPJ y la alusión al contexto y a la naturaleza del proceso de que se trata eliminan cualquier duda que se pudiera albergar sobre el alcance y sentido de tales afirmaciones, excluyendo con ello que pueda entenderse que se pone en cuestión la inocencia del solicitante de la indemnización.

Aun cuando no falta razón al voto particular en cuanto considera que la doctrina europea ha permitido en determinados casos establecer un estándar probatorio distinto según que se trate de dictar la sentencia penal o resolver la petición de reclamación(13), lo cierto es que el art. 294 LOPJ no permite esa nueva valoración de la prueba, pues obliga a constatar las razones que tuvo el juez penal al dictar la sentencia absolutoria y si lo fue por la prueba de la inocencia o por aplicación del derecho de presunción de inocencia sin permitir ese nuevo proceso de valoración y, menos aún, tener en cuenta otras circunstancias atinentes al devenir del proceso, a la actuación misma del encausado etc. Y esto es, precisamente, lo que merece el reproche realizado por el Tribunal Europeo no ya tanto a las resoluciones administrativas y judiciales que aplican el art. 294 LOPJ, independientemente del lenguaje que utilizan, sino a este precepto legal que hace depender la indemnización, única y exclusivamente, de los motivos de la sentencia penal para absolver en función de la aplicación o no de la aplicación de este derecho.

Así queda expresamente reflejado en la última de ellas, la STEDH de 16 de febrero de 2016 que resuelve dos demandas. En la primera el demandante había sido absuelto, en la segunda había sido objeto de so-

(13) Sostienen así los magistrados discrepantes la tesis del diferente estándar probatorio en la sentencia penal y en el procedimiento indemnizatorio, expuesta por MEDINA ALCOZ, L. "Los hechos en el derecho administrativo español. Una aproximación», en REDA núm. 177 abril-junio 2017, pág. 127, consistente básicamente en que el legislador puede exigir un estándar de prueba para valorar los hechos distinto según los intereses afectados, esto es, puede exigir una prueba más allá de probabilidades exigiendo que se despeje cualquier tipo de duda para imponer una condena, mientras que se limita a aplicar la tesis de la probabilidad de haber cometido el delito para descartar el derecho a la indemnización cuando pone al mismo nivel el derecho de quien ha sufrido prisión que el derecho del contribuyente. 
breseimiento provisional. El Gobierno español alegaba, en la primera, que para que los perjuicios sufridos con motivo de la detención provisional puedan ser compensados es necesario que la absolución o revocación de la condena sean pronunciadas en razón de que los hechos nunca han existido. Indica que, según la jurisprudencia, la indemnización en cuestión también puede concederse cuando el absuelto acredite su no participación en los hechos imputados. En la segunda que en el caso concreto, el Juez habida cuenta de las dudas existentes en torno a la participación del interesado en los hechos no ordenó un sobreseimiento libre sino provisional y que el demandante no lo recurrió. Indica que este sobreseimiento no tiene fuerza de cosa juzgada y que la suspensión del proceso no es definitiva para concluir que el art. 294 LOPJ solo reconocería un derecho a la indemnización cuando los tribunales hayan establecido que la persona puesta en detención provisional no ha cometido los hechos recriminados, ya sea con su absolución o decretando la absolución definitiva.

El Tribunal Europeo señala que, en lo que respecta al primer demandante, el Ministerio de Justicia rechazó la reclamación porque consideró que el art. 294 LOPJ no era aplicable al caso en la medida en que el demandante había sido absuelto por falta de pruebas de cargo suficientes que permitieran demostrar su participación en los hechos delictivos y no en razón de la inexistencia objetiva o subjetiva de los hechos.

$Y$ en lo que respecta al segundo, el Gobierno al interpretar literalmente el art. 294 LOPJ mantiene que la situación en cuestión no puede ser indemnizada en la medida en que el demandante no ha sido absuelto ni objeto de un sobreseimiento libre en razón de la inexistencia de los hechos imputados, siendo la absolución o el sobreseimiento firme las únicas decisiones expresamente mencionadas en el art. 294 LOPJ, siendo así que la sentencia señalo que el auto decidiendo el levantamiento del procesamiento por la inexistencia de indicios racionales respecto a la responsabilidad penal del procesado podía asimilarse a un auto de sobreseimiento libre poniendo fin a la instrucción mediante una declaración de no culpabilidad del acusado al igual que una sentencia absolutoria. No obstante, el juez contencioso administrativo recordó para denegar la indemnización que habría sido necesario tener la certeza de que éste no había participado en los hechos. En su condición de juez contencioso y no penal, consideraba que había indicios de la participación del demandante en la comisión de los hechos, aunque estos indicios no hubieran sido considerados suficientes por el juez de instrucción, y mencionó los que, en su opinión, hubieran podido demostrar la participación del interesado en los hechos de la causa. El Tribunal concluye que no puede exigirse al demandante que acredite su inocencia y que no corresponde a la jurisdicción contencioso administrativa concluir que el demandante es eventual- 
mente culpable, conclusión a la que no ha podido llegar el juez penal por falta de pruebas.

Y por ello, concluye el Tribunal Europeo, el razonamiento del Ministerio de Justicia fue posteriormente confirmado por las jurisdicción contencioso administrativa, que no ha hecho sino seguir la constante jurisprudencia interna en materia del art. 294 LOPJ, fundamentada en el criterio de la inexistencia subjetiva, es decir de la ausencia probada de participación del absuelto en los hechos delictivos. Por tanto, las jurisdicciones contencioso-administrativas, al ratificar el razonamiento del Ministerio en la aplicación de esta jurisprudencia y, en lo que respecta especialmente al segundo demandante, al realizar ella misma afirmaciones que son competencia del Juez penal, no ha remediado el problema que se planteaba en este caso.

Debe observarse que el voto particular en modo alguno distingue entre los supuestos de inexistencia objetiva y subjetiva de los hechos. No intenta basar su discrepancia en que el supuesto de que se trata no versa sobre la falta de participación sino sobre la inexistencia objetiva de los hechos. Se limita a discrepar de las sentencias europeas de condena insistiendo en que, en este caso, los términos empleados no conducen a afirmar que exista duda sobre la inocencia.

Despojada de su ornamento argumental, sólo cabe apreciar que la tesis expuesta por el voto particular no es sino una propuesta de lege ferenda, merecedora claro está de reflexión, a partir de la cual plantear la modificación por el legislador orgánico del art. 294 LOPJ, y que bien podría partir de que la Administración tuviera en cuenta determinados hechos, acreditados o no en el proceso penal, sobre los que realizara su propia valoración al margen de aquella de la que hubieran sido objeto en el proceso penal para llevar a la condena o absolución. Pero esto no es, se diga cómo se diga, lo que hoy por hoy permite el art. 294 LOPJ, al exigir que la Administración se limite a constatar las razones que tuvo el juez penal para absolver.

Por desgracia, en este punto, el voto particular adolece del mismo defecto que la sentencia de la mayoría. No se enfrenta con el verdadero problema: la forma en que el art. 294 LOPJ está concebido. Pero, además, conduce a un callejón sin salida. De haber sido ésta la opinión de la mayoría de los magistrados que componen el Pleno ¿habría podido plantar cara nuestro Tribunal Constitucional a la jurisprudencia del Tribunal Europeo de Derechos Humanos?

Al fin y al cabo, esto es lo que de bueno tienen los votos particulares. Que, a sabiendas de que lo son, no hacen doctrina pero permiten expresar una opinión discrepante aunque, en este caso, no haya sido, como parece, a la Sentencia de la mayoría sino un gol por la escuadra delTribunal Europeo de Derechos Humanos. 


\section{Epílogo. ¿En qué tejado está ahora la pelota?}

Expuestas las sentencias del Tribunal Constitucional y habida cuenta de que éstas han modificado la doctrina constitucional para ampliar nuestro derecho de presunción de inocencia del art. 24.2 CE a los límites establecidos en el Convenio Europeo de Derechos Humanos, debemos cerrar este comentario con la pregunta de ¿ahora qué?

La STC 8/2017 anula la sentencia del Tribunal Supremo que se limita a aplicar, al igual que la sentencia de la Audiencia Nacional y seguramente la resolución administrativa impugnada, la jurisprudencia sentada en aplicación del art. 294 LOPJ. Exactamente lo mismo que viene a hacer la STC 10/2017, al anular, esta vez, sentencia y acto por aplicación de la doctrina de la sentencia anterior.

Pero, como venimos de ver, no se trata en el caso español del lenguaje utilizado, lo que podría solucionarse poniendo, si cabe, el Ministerio de Justicia y después los Tribunales un mayor cuidado en la redacción de las sentencias, sino de la razón de decidir, esto es, del motivo que necesariamente han de tener en cuenta las resoluciones que desestiman la indemnización reclamada, que no es otro que la interpretación que ha venido realizando nuestra jurisprudencia de la única causa en función de la cual ha de resolverse según el art. 294 LOPJ, la petición de reclamación: que la absolución se haya basado en la inexistencia de los hechos.

Ya se trate de inexistencia objetiva o subjetiva, lo cierto es que el art. 294 LOPJ no permite tener en cuenta otros elementos relacionados con el contexto y naturaleza del proceso más allá de «la causa de la absolución" que, como acabamos de ver, queda reservada a los jueces de lo penal. Pero, siendo sinceros, tampoco la «inexistencia de los hechos imputados" permite otra interpretación distinta de la mantenida desde el año 1985 por la jurisprudencia contencioso-administrativa. Dada la relación existente entre esta reparación y el error judicial a la que el legislador orgánico liga este derecho y que parece admitir también la STC 8/2017, sólo pueden considerarse errores aquellos que se ponen de manifiesto sin necesidad siquiera de llegar a una sentencia condenatoria cuando queda demostrado, fuera de toda duda, que los hechos imputados y por los que individuo sufrió prisión no existieron.

$\mathrm{Si}$, como entiende la STC 8/2017, la vulneración del derecho a la presunción de inocencia viene dada por el tipo de argumentación de la sentencia del Tribunal Supremo en aplicación del art. 294 LOPJ, igual que la que llevó a las tres sentencias condenatorias a España, podía y debía haberse preguntado sobre si cabía otra interpretación del art. 294 LOPJ, esto es, tener en cuenta otros motivos distintos de la causa de la absolución o una interpretación distinta de la inexistencia del hecho, pues de no ser 
así, el planteamiento de la autocuestión de inconstitucionalidad sobre el art. 294 LOPJ habría estado servido.

El Tribunal Constitucional ha dejado, sin embargo, esta pelota en el tejado del Tribunal Supremo (no así en el Ministerio de Justicia que hasta ahora se ha limitado a seguir la jurisprudencia) que será quien se verá obligado a plantear, ahora ya sí, una cuestión de inconstitucionalidad si entiende que no existe otra interpretación del art. 294 LOPJ acorde con el contenido del derecho a la presunción de inocencia de acuerdo con la jurisprudencia europea, contenido que ha venido a integrar, a partir de las SSTC 8 y 19/2017, el del art. 24.2 CE. Hasta ahora, a pesar del giro jurisprudencial iniciado por las sentencias de 23 de noviembre de 2010, no lo ha conseguido y prueba de ello son las sentencias objeto de este comentario.

Y la solución apremia, no sólo porque las reclamaciones que dan pie a estas sentencias datan de 2007 y 2008, respectivamente, aunque los recursos de amparo se interpusieron en 2012, sino porque entre tanto están pendientes y se seguirán planteando otras muchas. 
LABURPENA: Giza Eskubideen Europako Auzitegiaren jurisprudentziaren ondorioz, Konstituzio Auzitegiak aurreko doktrina zuzendu behar izan du. Horretarako, errugabetasun-presuntziorako eskubidearen irismena zabaldu behar izan du, eta, administrazio-ebazpen zehatzaileetatik eta zigor-epaietatik harago, kalte-ordaina ukatzen duten erabakietara zabaldu du hori, Botere Judizialaren Lege Organikoaren 294. artikuluak eskatzen duen bezalaxe, errugabetasun-presuntzioaren printzipioa ezarri ostean akusatua absolbitu egin den baina delituzko egintzak egon ez zirela frogatu ez den kasuetarako.

GAKO HITZAK: Estatuaren erantzukizuna. Behin-behineko espetxealdia. Errugabetasun-presuntzioa. Botere Judizialaren Lege Organikoaren 294. artikulua. Egotzitako egitateen existentziarik eza, objektiboa zein subjektiboa.

RESUMEN: Fruto de la jurisprudencia del Tribunal Europeo de Derechos Humanos, el Tribunal Constitucional se ha visto obligado a rectificar su doctrina anterior extendiendo el alcance del derecho a la presunción de inocencia, más allá de las resoluciones administrativas sancionadoras y sentencias penales, a los pronunciamientos que, tal y como exige el art. 294 LOPJ, deniegan la indemnización en atención a que el acusado fue absuelto en aplicación del principio de presunción de inocencia sin que haya quedado probado que los hechos delictivos no existieron.

PALABRAS CLAVE: Responsabilidad del Estado. Prisión provisional. Presunción de inocencia. Artículo 294 de la Ley orgánica del poder judicial (LOPJ). Inexistencia objetiva y subjetiva de los hechos imputados.

ABSTRACT: As a result of the case law by the European Court of Human Rights, the Constitutional Court was compelled to rectify its former doctrine by broadening the scope of the right to the presumption of innocence beyond punitive administrative resolutions and criminal judgments to rulings that as art. 294 of Judiciary Act requires, deny the award of damages on the ground that the accused was acquitted due to the application of the principle of innocence without having been proved that the criminal offences did not exist.

KEYWORDS: Responsibility of the State. Provisional detention. Presumption of innocence. Art. 294 of Judiciary Act. Factual and Subjective inexistence of the charges. 